\title{
Editor's Remark
}

We are very glad to present Volume 50 as a special issue. The first volume was edited by the late Professor Totsuji Kametani, Founder of our Journal, and was published in 1973. During the past 26 years, our Joumal has contributed much to the development of heterocyclic chemistry as well as natural product chemistry throughout the world. This is due to publish many novel and active papers and also to be contributed by Honorary Editorial Associates and Honorary Advisors to Editorial Board, to whom the editor deeply acknowledges. Moreover, the editor extends special thanks to the referees who have contributed so much to the development of our Journal;

Our Joumal prints COMMUNICATIONS, PAPERS, NOTES, and REVIEWS which aro accepted to be published by the referees. NEW HETEROCYCLIC NATURAL PRODUCTS and TOTAL SYNTHESIS OF HETEROCYCLIC NATURAL PRODUCTS are listed at the end of each issue. The editor continues to strive for improving the quality of the papers published in our Journal in order to contribute to a development of heterocyclic, natural, and medicinal chemistry. On this occasion the editor acknowledges heartfelt cooperation by the referees; Honorary Editorial Associates, and Honorary Advisors to the Editorial Board. The editor anticipates a contribution of splendid manuscripts on a wide range of the chemistry of heterocycllc compounds.

Finally, the editor extends special thanks to Mr. Koichi Kametani, son of the Founder of our Joumal, for his devoted collaboration to our Joumal.

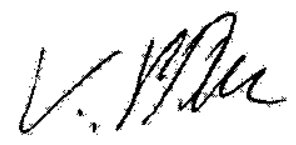

Keiichiro Fukumoto

The Editor of HETEROCYCLES 